\title{
The Effects of HealthService Delivery on Patient Satisfaction: (Nekemte Public hospital)
}

\author{
Dame Yemane Adula ${ }^{1} \quad$ Gudata Abara Chali ${ }^{2}$ \\ 1.Lecturer, Department of Management, College of Business and Economics, Rift Valley University, Ethiopia \\ 2..Assistant Professor, Department of Accounting and Auditing, Faculty of Business and Development, Wollega \\ University, Ethiopia
}

\begin{abstract}
The success of any organization depends on its customers and many organizations attempt to establish strong relationship with their customers to achieve customer satisfaction. The overall objective of the study was to examine the effects of health service delivery on patient satisfaction in Nekemte Public hospital. Therefore the study tried to examine the level of customer satisfaction in the hospitals. Both qualitative and quantitative type of data was used for the purpose of the study.To achieve the objectives of this study; data was collected through structured questionnaire from a sample of 400 patients of Nekemte Public hospital. These respondents were selected using purposive sampling technique. Moreover, semi structured interview with medical, inpatient, outpatient and emergency directors was conducted to supplement data collected using questionnaire. SPSS version 20.00 software was used to process the primary data collected through questionnaire. The data collected from the questionnaire were analyzed using Statistical tools such as mean, standard deviation, correlation, and multiple regression analysis. The finding of the study indicates that all service quality dimensions (tangibility empathy, reliability, assurance and responsiveness) are positively and significantly correlated with customer satisfaction.Generally the results of multiple regression analysis indicated that, except reliability the four service quality dimensions have positive and significant influence on customer satisfaction. The result of the study indicated that the hospital didn't provide fast service to their customers.Finally, to enhance customer satisfaction, the hospital should attempt to maintain consistent service quality at or above customers' expectation by assessing all the service quality dimensions regularly.
\end{abstract}

Keywords: Tangibility, Empathy, Reliability, Responsiveness, Assurance and Patient Satisfaction

DOI: $10.7176 / \mathrm{JMPB} / 55-02$

Publication date:May $31^{\text {st }} 2019$

\section{Introduction}

According to Cauchick and Salomi,(2004) many service providers have pursued to enhance their performance and effectiveness in search of achieving differentiation in the market. Example they attempt to convince customers that their quality is superior to the competitors. Furthermore, the importance of service sector has sharply increased at both developed and developing countries. Over $75 \%$ of all US jobs now reside in services industries. Service industries have increasingly been considered as an important sector, making up the majority of the economies, in particular those of developed nations (Akbaba, 2006; Jensen, 2011; Petri et al. 2012). In today's competitive market providing high quality service is the key for a sustainable competitive advantage.Satisfied customers form the foundation of any successful business as customer satisfaction leads to repeat purchase, brand loyalty and positive word of mouth (Angelova and Zekiri, 2011).

Hospital is a residential establishment which offers medical care services consists of diagnostic, observational, therapeutic,and rehabilitative services for persons who are suffering orsupposed to be suffering from a disease or injury. Its fundamental job is the treating and caring forpatients(Singh,2010). Healthcare sectors are considered to be the major service sector for a country as it plays a vital role to develop and maintain a healthy human capital to achieve national goals. In many countries, healthcare sector has also become a highly competitive and fast growing service industry (Jabnoun and Chaker, 2003).

\section{Research Design and methodology}

The study employed cross sectional survey design. Descriptive and inferential statistics were used for the purpose of this study. The study used both qualitative and quantitative type of data. The study employed both primary and secondary sources of data. The data was collected from the selected sample of patients' who visit the hospital two or more than two times. Primary data was collected through questionnaire, observation and personal interview. Secondary data was collected from studies done before, like journal, articles and other references related to the topic.

Nekemte Public hospital was conveniently chosen among different hospitals found in Ethiopia as a study area, because this hospitalis nearest and convenient to the researchers to collect the data and also the contribution of patient satisfaction in these areas is not researched. The target population of the study is the patients of the selected hospitals. The accurate number of the target population is unknown therefore the researchers selected 
400 samples of patients for the study. The researchers give equal chance for this hospital to select the sample, meaning 200 samples of patients was selected from each hospital. Furthermore, Crouch's (1984) recommends that "minimum sample sizes for quantitative consumer surveys are of the order of 300 to 500 respondents". Since the data was collected from 400 patients by using purposive sampling technique.

For the purpose of data collection, the researchers were used self-administered closed-ended questionnaires and semi structured interviews. Semi-structured interview was conducted with the medical director, inpatient, outpatient and emergency directors of the two hospitals. The researchers were observed the campus/compound of the two hospitals.

This section deals with data processing procedures such as editing, coding, classification and tabulation of the collected data. Descriptive statistics such as percentage, frequency, mean standard deviation and inferential statisticalmethods such as: correlation and multiple regression analysiswere used to analyze the data. The Statistical Package for Social Science (SPSS) version 20 software was employed to analyze the data collected through questionnaire.

\section{Result and Discussion}

Descriptive Statistics results and discussion

Table 1: Description of Service Quality Dimension and Patient satisfaction

\begin{tabular}{|l|l|l|l|}
\hline \multirow{2}{*}{ No } & \multicolumn{1}{|l|}{ Variables } & \multicolumn{2}{l|}{ Average mean and std. dev. } \\
\cline { 3 - 4 } & Mean & Std. Deviation \\
\hline 1 & Tangibility & 3.3084 & .72784 \\
\hline 2 & Reliability & 3.5180 & .92629 \\
\hline 3 & Assurance & 3.5961 & .78426 \\
\hline 4 & Responsiveness & 2.7875 & .93576 \\
\hline 5 & Empathy & 3.2871 & .94481 \\
\hline 6 & Patients satisfaction & 3.1968 & .97016 \\
\hline
\end{tabular}

Source: Own survey result, 2019

As it is clearly indicated in the above table 4.1the mean score shows the perception of patients on the dimensions of service quality. Based on the above table the overall perceived mean value and std. deviation of tangibility is 3.30 and 0.727 , reliability 3.51 and 0.927 , assurance 3.59 and 0.784 , responsiveness 2.78 and 0.935 , empathy 3.28 and 0.944 , patient satisfaction 3.19 and 0.97 respectively.Having all the above pointsthe overall perceived mean value of tangibility, reliability, assurance and empathy are above neutral scale. This implies that majority of the respondents were satisfied with majority of dimensions of service quality. To the contrary, responsiveness has mean score of 2.78 which is below neutral scale. Therefore, from this it could be concluded that majority of the respondents were dissatisfied with responsiveness of the two hospitals. So the hospital should develop strategies to improve their responsiveness and to satisfy patients in the hospital.

The researchers were made observation for outpatients during the waited time for received services at different service delivery stations (reception, medicalrecords, laboratory and pharmacy).With regard to the waiting times the reception and laboratory tests had the longest waiting times. Moreover there was also a serious time management problem in the hospitals; majority of the time examination offices were opened at morning at 2:45 and after the specified time, especially in Nekemte Public hospital. And also the card room system was not computerized. In general, as the survey result and observation made in the hospital indicates that there are tasks that hospital has to do on the variables of responsiveness to improve patients' satisfaction.

\section{Results of Inferential Statistics}

Table 2.Pearson Correlation analysis Result

\begin{tabular}{|l|l|l|}
\hline Service Quality Dimensions & Patients satisfaction & \\
\cline { 2 - 3 } & Pearson Correlation & Sig. (2-tailed) \\
\hline Tangibility & $.582^{* *}$ & .000 \\
\hline Reliability & $.598^{* *}$ & .000 \\
\hline Assurance & $.655^{* *}$ & .000 \\
\hline Responsiveness & $.638^{* *}$ & .000 \\
\hline Empathy & $.760^{* *}$ & .000 \\
\hline
\end{tabular}

**. Correlation is significant at the 0.01 level (2-tailed). $\quad \mathrm{N}=400$

Source: Own survey result, 2019

The results in the above table indicates that, there is positive and significant relationship between independent variables of tangibility, reliabilityassurance, empathy and responsiveness, with the dependent variable of patientssatisfaction at $99 \%$ confidence level $(\mathrm{P}<0.01)$. The highest correlation is signified by empathy $(r=0.760)$, followed by assurance $(r=0.655)$, responsiveness $(r=0.638)$, reliability $(r=0.598)$ and tangibility $(r=$ 
0.582). This indicates that empathy plays a great role on enhancing patients' satisfaction in the hospital.Generally all the independent variables are significantly correlated with the dependent variable (patient satisfaction), at 0.01 significance level. The degrees of relationship between the independent variables such as empathy, responsiveness and assurance have the highest correlation with the dependent variable (patient satisfaction). And the degrees of relationship between independent variables such as tangibility and reliability have moderate correlation with the dependent variable.

Multiple Regression Analysis

Table 4.3. Coefficients of service quality dimensions

\begin{tabular}{|l|l|l|l|l|l|}
\hline Model & Unstandardized Coefficients & Standardized Coefficients & $\mathrm{t}$ & \multirow{2}{*}{ Sig. } \\
\hline Independent variables & $\mathrm{B}$ & Std. Error & Beta & & \\
\hline $1 \quad$ (Constant) & -.331 & .148 & & -2.233 & .026 \\
\hline Tangibility & .158 & .050 & .119 & 3.134 & .002 \\
\hline Reliability & .081 & .045 & .077 & 1.817 & .070 \\
\hline Assurance & .203 & .057 & .164 & 3.578 & .000 \\
\hline Responsiveness & .202 & .040 & .194 & 5.049 & .000 \\
\hline Empathy & .434 & .045 & .422 & 9.604 & .000 \\
\hline
\end{tabular}

a. Dependent Variable: Patients satisfaction $\quad \mathrm{N}=400$

** Significant at $\mathrm{p}<0.01$

Source: Own survey result, 2019

The above coefficients table 4.3 illustrates the influence of service quality dimensions on patient satisfaction. At this point using this multiple regression coefficient results, the proposed hypotheses for this study were tested as follows.

H1: Tangibility has positive and significant influence on patient satisfaction.

The result of multiple regression analysis of the above table 4.3 above clearly indicates that tangibility has significant influence on patient satisfaction $(p<0.01)$. Besides, the value of standardized beta is $(\beta=.119)$, this implies that a one percent increase in tangibility results in 11.9 percent increase in patient satisfaction. Hence, the above proposed hypothesis is accepted.

H2: Reliability has positive and significant influence on patient satisfaction.

The above table 4.3 demonstrates that reliability has positive but insignificant influence on patient satisfaction in the hospital $(p>0.05)$. Besides, the table depicts the value of standardized beta $(\beta=.077)$ shows that there is no significant influence of reliability on patient satisfaction. This implies that a one percent increase in reliability results in 7.7 percent increase in patient satisfaction. Therefore the above proposed hypothesis is rejected at $(\mathrm{p}<$ $0.05)$.

H3: Assurance has positive and significant influence on patient satisfaction.

The result of multiple regression analysis in the table 4.3 above clearly indicates that assurance has significant influence on patient satisfaction $(p<0.01)$. Besides, the value of standardized beta is $(\beta=.164)$ demonstrates that the positive influence of assurance on patient satisfaction. This implies that a one percent increase in assurance results in 16.4 percent increase in patient satisfaction. Thus, the above proposedhypothesis is accepted.

H4: Responsiveness has positive and significant influence on patient satisfaction.

The above table 4.3 demonstrates responsiveness which has a significant influence patient satisfaction $(\mathrm{p}<0.01)$. Besides, the table shows the value of standardized beta in the hospital is $(\beta=.194)$ shows that the positive influence of responsiveness on patient satisfaction. This implies that a one percent increase in responsiveness results in 19.4 percent increase in patient satisfaction. Therefore; the above proposed hypothesis is wellaccepted.

H5: Empathy has positive and significant influence on patient satisfaction.

The coefficient of empathy in the multiple regressions on the above table 4.3illustrates that in the hospitalsempathy has significant influence on patient satisfaction $(\mathrm{P}<0.01)$. Besides, the value of standardized beta is $(\beta=.422)$ point outs that the positive influence of empathy on patient satisfaction. This impliesthat one percent increase in empathy results in 42.2 percent increasein patient satisfaction. Hence, the above proposed hypothesisis well accepted.

In general, the multiple regression analysis of the above table 4.3 clearly demonstrates thatout the five independent variables or service quality dimensions, four independent variables orservice quality dimensions (tangibility, assurance, empathy and responsiveness) have a positive and significantinfluence on the dependent variable (patient satisfaction) in the hospitals.On the other hand, reliability has a positive but insignificant effect on customer satisfaction. The result of this study indicates that empathy is the most important factor to have apositive and significant effect on patient satisfaction. 


\section{Conclusions}

Based on the data analysis and presentation made above, the researchers conclude the following major points. The main objective of the study was to examine the effects of health service delivery on patient satisfaction: Nekemte Public hospital.

The finding of the study indicates that majority of the patients were satisfied with majority of the variables of tangibility except with the items of availability of enough medical supplies, enough waiting chairs in the hospitalsand the reception area is comfortable for patients.Furthermore the result of reliability shows that majority of the patients were satisfied with the items of reliability.And also the finding of the study indicated that majority the patients were satisfied with all individual variables of assurance. With regard to the individual items of responsiveness the result ofthe study indicates that majority of the respondents were dissatisfied with almost all individual variables of responsiveness. The study concluded that the willingness to help customers and provision of fast response to patients in the hospital is very low.

The result of the individual items of empathy shows that majority of the respondents were satisfied with the individual items of empathy. So based on this finding we can conclude that the degree of caring and giving individualized attention to patient is good but still it needs improvement. With regard to thePearson correlation analysis, the study clearly shows that the five service quality dimensions namely tangibility, reliability, assurance, empathy and responsiveness are positively and significantly correlated to patient satisfaction in the hospitals. To sum up,the multiple regression analysis notifies that, the four service quality dimensions includingtangibility, responsiveness, assurance and empathy have positive and significant effect on patient satisfaction. Finally the study indicated that, except reliability the four service quality dimensions significantlyexplain the variations in patient satisfaction.

\section{Recommendations}

Based on the findings and conclusions made above, the researchers forwarded the following recommendations for enhancing service delivery system in the hospital. To improve patient satisfaction level and develop loyal customers, the hospital should give greater awareness on enhancing communication with its customers, by developing effective relationship and providing individualized attention to them. Furthermore, responsiveness was considered as one of the most important factors influencing patients' satisfaction. However, the customers of the hospital were dissatisfied in this regard. So the hospital should handle this problem by delivering services at promised times, providing fast response and handling customer's complaints effectively. The hospital should implement quality management systems in order to minimize poor service delivery system. And also it is advisable to provide proper training on ethics, skills, courtesy, promote good spirit, and attitude of employees towards patients, to improve satisfaction level. It is also highly recommended that the required and adequate amount of drugs should be available in the hospital.

The ministry of health should give more attention on providing drugs and other modernequipment such as sitting chair for patients and modern laboratory equipments for both hospitals. And also the regional health bureau should supervise, follow up the activities of the hospital and provide training for employees so as to improve patient satisfaction in the hospitals. Finally the hospital should attempt to maintain consistentservice quality at or above customers' expectation by assessing all the servicequality dimensions regularly. This study was conducted to examine the effects of health service delivery on patient satisfaction: Nekemte Public hospital However, future research may investigate on the effects of health service delivery on patient satisfaction: comparative analysis public with private hospitals. Inpatients were excluded from this research, so future research may investigate by including the inpatients.

\section{References}

Agency for Health care Research and Quality. (2006). CAHPS Hospital Survey Chart book: What Patients Say about Their Experiences with Hospital Care. Available from URL: http://www. cahps.ahrq.gov/content/ncbd/PDF/Hcahps Chart book pdf. Accessed 30 January 2009.

Akbaba, A. (2006). Measuring Service Quality in the Hotel Industry: A study in a Business Hotel in Turkey, Hospitality Management, Vol. 25, pp. 170-192.

Angelova,B. and Zekiri,J. (2011). Measuring Customer Satisfaction with Service Quality Using American Customer Satisfaction Model (ACSI Model).International Journal of Academic Research in Business and Social Sciences, Vol. 1, No. 3

Aleksieva, N. M. (2010). Service quality perception analysis to define loyalty in the airlineindustry.Retrieved June 15, 2012, from:https://www.politesi.polimi.it/...NMA\%20\%20Thesina\%20Text.pdf

Birna A. (2006) The quality of hospital services in eastern Ethiopia: Patient's perspective. Ethiopia Health Dev: 199-200.

Cauchick, P. and Salomi, G.(2004), A review of models for assessing service quality.Journal of Retailing .Vol. 14, No. 1, Pp. 12-30. 
Crouch, S. (1984), Marketing research for managers, Butterworth-Heinemann,London, UK.

Daniel, C. \&Berinyuy, L.P. (2010), Using the SERVQAL Model to assess Service Quality and Customer Satisfaction, [online], Available from http://urn.kb.se/resolve?urn= urn:nbn:se:umu:diva-35008. [Accessed: $27^{\text {th }}$ May 2013]

Hasin, M. A. A., Seeluangsawat, R. and Shareef, M. A. (2001). Statistical measures of customer satisfaction for health care quality assurance: a case study. International Journal of Health Care Quality Assurance.Vol.14 No.1, pp. 6- 13.

HEU (2003) Bangladesh National Health Accounts 1999- 2000. Dhaka: Health economics unit, ministry of health and family welfare, government of Bangladesh, 63-71.

Jabnoun, N. and M. Chaker, (2003).Comparing the implementation of quality management systems in the Service Quality, 13(4): 290-299.

Jensen, J. B. (2011). Global Trade in Services: Fear, Facts, and off shoring, Washington, DC: Peterson Institute for International Economics.

Karunamoorthi, K., Rajalakshmi, M., Makesh, S. \&Yohannes, A. (2009). HIV/AIDS patients satisfactory and their expectations with pharmacy service at specialist antiretroviral therapy units. European Review for Medical and Pharmacological Sciences, 13:331-339

Kotler, P. (2003): Marketing Management; 10th edition; New Jersey, Prentice-Hall.

Lech, M.M. \&Petryka, I. 2002. Evaluation of patients' satisfaction in relation to private or public health care providers' .WiadLek. 55 Suppl 1:313-20

Lovelock H. Christopher and J Wirtz J. (2004): Service Marketing People Technology C.N.

Ministry of Health.(2002/2003).Health Sector Strategy.Ministry Of Health, Addis Ababa.

Mohammad, S.A.A. and Alhamadani, M.Y.S. (2011), Service quality perspectives and customer satisfaction in commercial banks working in Jordan, 14 (2011): 61- 72.

Mok, C., Sparks, B. \&Kadampully, J. (2013), Service quality management in Hospitality Tourism and Leisure.

Ndubisi, N. O. (2004). Cross Cultural Management. Understanding the salience of cultural dimensions on relationship marketing, its underpinnings and aftermaths, Vol. 11, No. 3.

Offei( 2004). Healthcare Quality Assurance Manual For Sub-Districts'

Parasuraman, A., Berry L. and Zeithmal V.(1994). Reassessment of expectations as acomparison standard in measuring SQ: Implications for Further Research. Journal ofMarketing, 58(1), pp 111-124.

Parasuraman, A., Zeithamal, V.A. and Berry, L.L. (1988). SERVQUAL: A multiple-item scale for measuring consumer perceptions of service quality, Journal of Retailing, 64(1), 12-40.

Petri, P.A., Plumer, M.G. And Zhai, F. (2012). ASEAN Economic Community: A General Equilibrium Analysis, Asian Economic Journal, Vol. 26, pp. 93-118.

Singh, R. (2010). Patients' perception towards GovernmentHospitals in Haryana. VSRD Technical \&NonTechnical Journal, 1 (4), 198-206.

Zineldin, M. (2006).The quality of health care and patient satisfaction. International journal of health care quality assurance, 19 (1), 60-92, doi: 10.1108 .

Zeithaml, V. A., \& Bitner, M. J. (2008). Services Marketing. New York: McGraw-Hill. 